\title{
Experimental study of flying ballast at high speed railway applying track vibration
}

\author{
Mohammad Reza Talaee* and Behtash Hakimzadeh \\ School of Railway Engineering, Iran University of Science and Technology (IUST), Tehran, Iran
}

Received: 20 July 2019 / Accepted: 27 March 2020

\begin{abstract}
In this paper the complete approach is introduced for study of Ballast flying in wind tunnel considering track vibrations and aerodynamic loads. The air velocity profile under high speed train with speed of $300 \mathrm{~km} / \mathrm{h}$ is introduced using an analytical approach and the intensity of under train wind is defined. About $50 \mathrm{~kg}$ of Iranian high speed railway ballast is adopted by random sampling and classified according to mass and aerodynamic shape. The critical velocities of ballast moving are measured by wind tunnel for all classification to obtain the ballast flying probability factor (BFPF) at two modes of with and without track vibration. Also, the conventional ballast flying risk mitigation methods in wind tunnel are reviewed and a new strategy for ballast flying risk mitigation is introduced and tested, based on the design of track surface by a special sieved group of ballasts with minimum flying probability factor. Results show that the BFPF increases in presence of vibration and the minimum value of BFPF is occurred at mass range of 150-200 g. It's stated that application of this group on the track surface may prevent from ballast flying due to passing of train with maximum speeds of $300 \mathrm{~km} / \mathrm{h}$.
\end{abstract}

Keywords: Flying ballast / high speed train / air velocity / BFPF / track vibration

\section{Introduction}

Railway is one of the conventional ways for transferring goods and passengers in all over the world and decreasing the travel time is an important factor for attracting passengers. In high speed trains the aerodynamic loads are not negligible, therefore some important phenomena such as cross wind, slipstream, aerodynamic loads (lift and drag), pressure waves in tunnels, train nose aerodynamic shape and their side effects are under focused by researchers [1-20]. Flying ballast is another aerodynamic hazard in high speed railway transportation that has attracted the attention of researchers. This phenomenon is happen due to the interaction of produced aerodynamic flow under the train and the track surface in a ballast line. Some researches show that when the train speed is over than $260 \mathrm{~km} / \mathrm{h}$, probability of ballast motion will increase dramatically [21]. Railway manual workers and other maintenance operators near the track, can be threaten by side effects of this phenomenon, therefore several studies are done in this area using field measurements, wind tunnel tests and numerical simulations. Kwon et al. [22] studied on induced wind from Korean high speed train by field measurement and wind tunnel tests. They analyzed

\footnotetext{
* e-mail: mrtalaee@iust.ac.ir
}

the effect of this wind on ballast flying and investigated a parameter called ballast flying probability factor (BFPF) and showed that the air velocity under trains with 300$350 \mathrm{~km} / \mathrm{h}$ are about $25-30 \mathrm{~m} / \mathrm{s}$, respectively for KTX high speed train. Ido et al. [23] analyzed the effect of smoothing of the train beneath, on the produced air velocity and then on flying ballast. In order to achieve to minimum air velocity under high speed train, they setup different models of train under floor in wind tunnel and analyzed the effect of effective roughness on the velocity profiles. Results showed that the magnitude of air velocity under high speed train will be lower if the train beneath are smoother. Quinn et al. [24] studied on the mechanical and aerodynamic forces applied to the ballast in high speed train passage by full scale experimental tests. The main goal of this research was to understand the reasons of ballast flying initiation. They measured air pressure and velocity at different locations of high speed line and understood that none of mechanical and aerodynamic forces alone can lead to ballast flight. Lazaro et al. [25] studied the effective parameters on ballast flight by experimental tests in Madrid-Barcelona high speed line and measured air velocity at different heights from track surface. Results showed that the air velocity under high speed train is function of train passing time and this air stream is similar to turbulent Couette flow. Rocchi et al. [26] studied the flying ballast due to air stream under high 
speed train by numerical and experimental methods. They validated a Computational Fluid Dynamics (CFD) model to simulate the air stream under high speed train. Permoli et al. [27] studied on flying ballast effective parameters by wind tunnel tests on a full scale model of Italian high speed track and analyzed the effect of height of ballast level and stone shape on this phenomenon. Results showed that $3 \mathrm{~cm}$ lowering the level of the ballast related to top surface of traverse has a positive effect on the flying ballast phenomenon. Barbosa et al. [28] presented a new inspection method for railway tracks by combination of inertial measuring system and a specific method for data treatment. The effect of vibration on the railway track is analyzed by other researchers, too. Yau et al. [29] proposed a numerical model to evaluate the high speed train - bridge interaction and found that the most effective parameter on bridge response is the mass ratio of high speed train to bridge. Naeimi et al. [30] studied the effect of rail irregularities on dynamic response of sleepers by analytical and experimental approaches which showed that these irregularities should be mentioned as an important factor in stability analysis. Bogacz et al. [31] analyzed some effective parameters on the interaction of wheel set and railway ballasted track and compared the results of numerical and experimental models. Metrikine et al. [32] studied the effect of low frequency vibrations on railway sub structure by experimental method and found that the frequency-dependence of the identified stiffness don't explain by measured data.

As shown all researchers are focused on effectiveness of some parameters on ballast flying and their weights. In this work, despite of the conventional works [22], the BFPF is determined considering the track vibration. Also, the conventional ballast flying risk mitigation methods in wind tunnel are reviewed and a new strategy for ballast flying risk mitigation is introduced and tested, based on the design of the track surface by a special sieved group of ballasts that have minimum flying probability factor. For more actual conditions of the simulation, this strategy is tested in wind tunnel applying vibration of a track. The novelties of the work can be listed as:

- Introducing the complete procedure for studying the flying ballast phenomenon.

- Determination of BFPF considering track vibrations which simulates more actual conditions of track in wind tunnel.

- Definition of a new risk mitigation strategy for high speed trains with maximum speed of $300 \mathrm{~km} / \mathrm{h}$ which requires minimum maintenance process.

\section{Calculation and method}

Experimental study of the ballast flight phenomenon by wind tunnel tests needs to a specific setup and special scenarios. Some parameters such as air velocity profile and intensity of strong wind under train, physical and aerodynamic properties of sample ballasts should be determined before starting of tests. The steps of procedure are explained in this section:

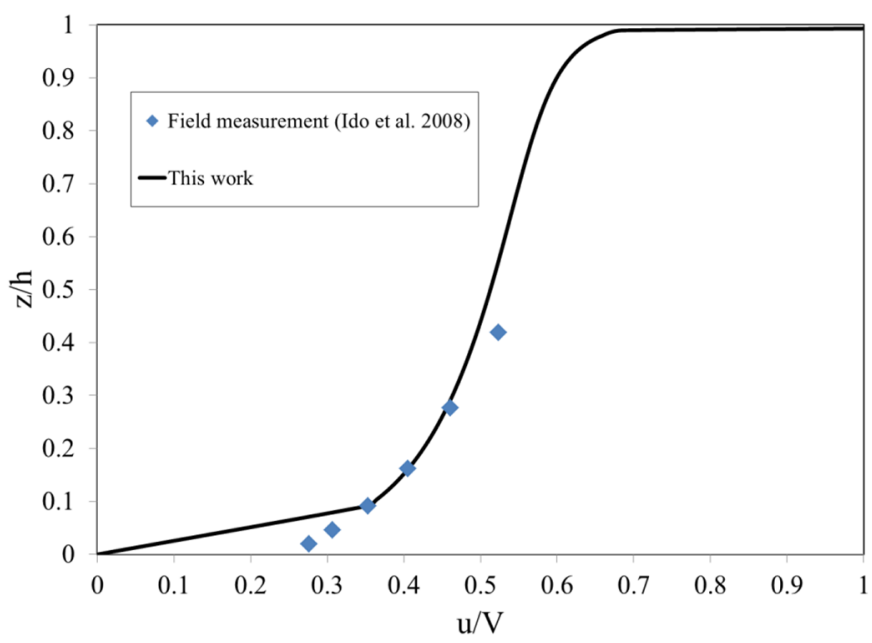

Fig. 1. Air velocity profile under the high speed train with speed of $300 \mathrm{~km} / \mathrm{h}$.

\subsection{The air velocity profile under high speed train}

Since, field measurements are showed that induced air velocity under the high speed train is more than track side [15] and maximum under train air velocity occurs at middle zones of track between the rails [5], therefore this area is more critical for flying ballast phenomenon. At first the air velocity profile under high speed train can be determined by an analytical solution of turbulent Couette flow [33] that is shown as below:

$$
\begin{gathered}
\frac{u}{u^{*}}=2.5 \ln \frac{z}{z_{0}} \\
\frac{u}{u^{*}}=2.5\left(\ln \left(\frac{\sin \left(\frac{\pi z}{2 h}\right)}{\pi z_{01} / 2 h}\right)-\ln \left(\cos \frac{\pi z}{2 h}\right)\right) \\
u^{*}=\frac{V}{2.5\left(\ln \frac{2 h}{\pi z_{01}}+\ln \frac{2 h}{\pi z_{02}}\right)}
\end{gathered}
$$

where $u$ is the horizontal velocity, $u^{*}$ is friction velocity, $z$ is vertical coordinate, $z_{0}$ is the equivalent roughness of track and train beneath surface as $z_{01}=\frac{k_{s 1}}{30}$ and $z_{02}=\frac{k_{s 2}}{30}$, respectively, $k_{s}$ is the surface roughness and $h$ is vertical distance between the track and train beneath surface and $V$ is the train speed. Velocity profile can be determined in viscous sub layer and fully developed turbulent region by equations (1) and (2) respectively.

In this study a usual high speed train is adopted with maximum speed of $300 \mathrm{~km} / \mathrm{h}$ that the equivalent roughness of train covered under floor is about $0.003 \mathrm{~m}$ [33]. Also, the equivalent roughness of ballasted track is considered about $0.024 \mathrm{~m}$ [21]. The calculated velocity profile is shown in Figure 1 which shows the base of Couette flow beneath of the train. The calculated profile is compared with the real measured velocity profile under Japanese high speed train at the speed of $300 \mathrm{~km} / \mathrm{h}[23]$ as shown in Figure 1. 


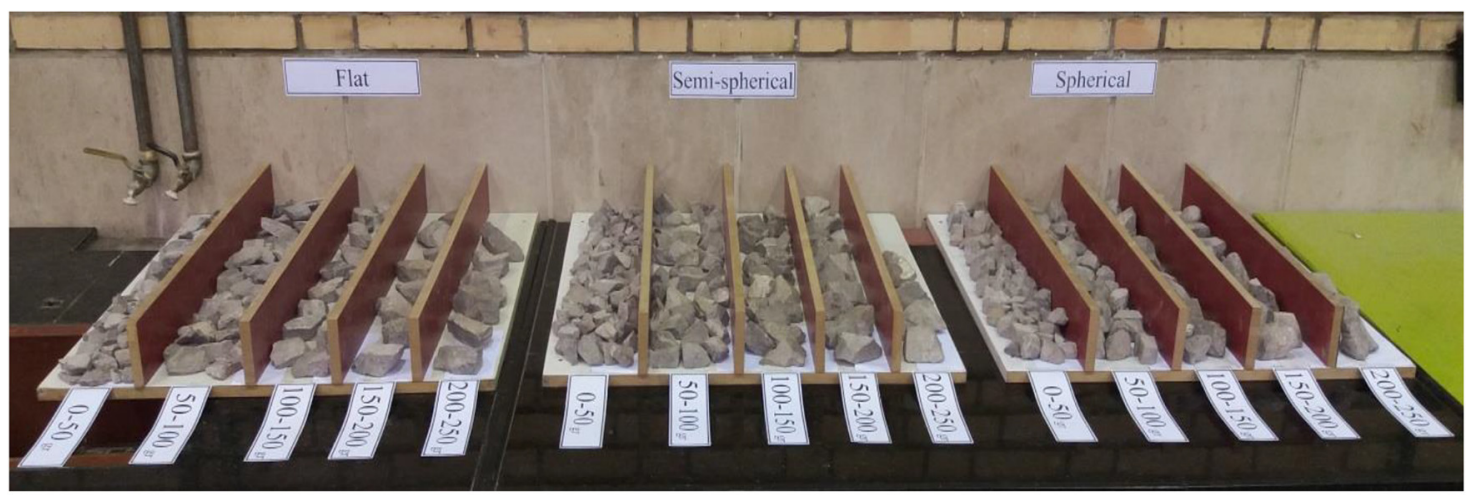

a. Ballasts at all shape and mass ranges

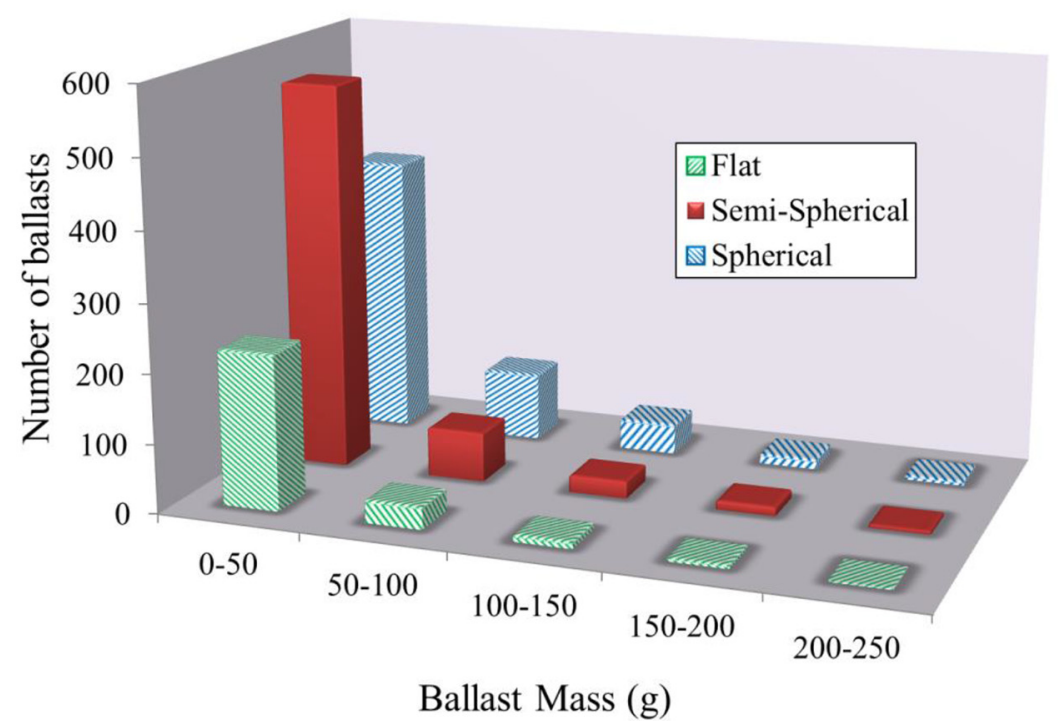

b. Number of categorized ballasts at each shape group and mass

Fig. 2. Classified ballasts at aerodynamic shape groups and mass ranges.

Regarding good consistency of results, it can be seen that the introduced relation (1)-(3) can be applied for estimation of velocity profile beneath the train with good accuracy as needed for calculation of BFPF. Our goal from calculation of wind velocity profile under the train and average velocity is to have an estimation of order of magnitude of induced wind intensity of a train with specified steering velocity. The average velocity of undertrain wind profile plays this role and further can be applied as a tool for the future estimation of flying ballast probability factor (BFPF). In addition it is known that there are some velocity fluctuations around the average which is due to the turbulence of wind flow under the train. These velocity fluctuations are considered too in determination of critical wind velocities of $V_{\min }$ and $V_{\max }$ in calculation procedure of BFPF as will be discussed later. Thus the intensity of flow under train ( $\left.V_{\text {Wind }}\right)$ which is one of important parameters for calculation of ballast flying probability factor is defined as the average of velocity profile and is equal to $30.7 \mathrm{~m} / \mathrm{s}$ for the considered train here with steering velocity of $300 \mathrm{~km} / \mathrm{h}$. This average of velocity profile is calculated by numerical integration of velocity profile of underneath train using Trapezoidal rule.

\subsection{Ballast classification in mass and shape}

At the next step the sample ballast is classified due to mass and aerodynamic shapes. Due to this purpose a random sample of $50 \mathrm{~kg}$ of Iranian railway ballast is adopted and classified due to the weight at groups of $50 \mathrm{~g}$ and three shapes of spherical, semi-spherical and flat as shown in Figure 2a. This sample ballast is located in 4th group according to Iran code 301 [34].

All the ballasts are weighted with $0.1 \mathrm{~g}$ resolution and separated in flat, semi-spherical and spherical aerodynamic shapes by inspection. Aerodynamic properties of three shapes are demonstrated in Table 1. As shown in Table 1 unlike spherical, usually flat ballast has more resistance to motion because of maximum contact area with lower surface and minimum exposed area to wind stream that leads to higher stability. 
Table 1. Aerodynamic properties of three ballast shapes.

\begin{tabular}{|c|c|c|c|c|}
\hline Aerodynamic shape & Image & $\begin{array}{l}\text { Seat area with } \\
\text { down surface }\end{array}$ & $\begin{array}{l}\text { Exposed area } \\
\text { to wind stream }\end{array}$ & $\begin{array}{l}\text { Stability at } \\
\text { released mode }\end{array}$ \\
\hline Semi-Spherical & & Large & Medium & Medium \\
\hline
\end{tabular}

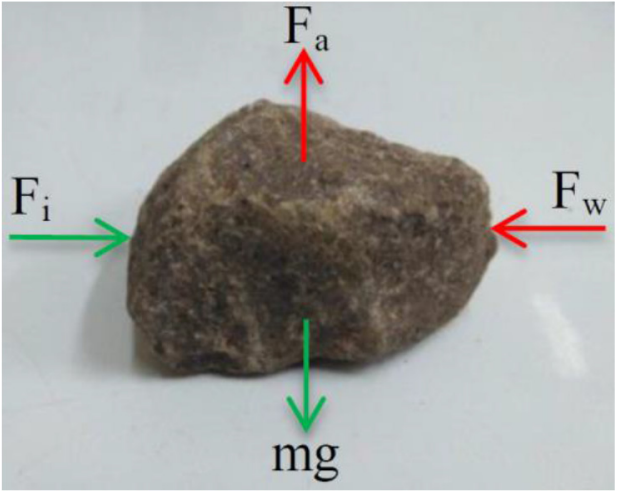

Fig. 3. Force equilibrium on typical ballast under high speed train.

Figure $2 \mathrm{~b}$ shows the distribution of ballasts at each mass range of all groups of aerodynamic shapes. It can be seen that the number of small ballasts at mass range of $0-50 \mathrm{~g}$ is more than others at all shape groups and the number of large ballasts reduces to zero up to $250 \mathrm{~g}$.

\subsection{Ballast flying probability factor}

The force diagram of typical ballast under high speed train is involved aerodynamic and mechanical forces [35] as shown in Figure 3.

Where $F_{w}$ is the force of induced wind of high speed train which acts on ballast surface, $F_{a}$ is the force of ballast acceleration induced by track vibration, $F_{i}$ is the interlock force due to other ballasts and $m g$ is the gravitational force. When ballast is freely placed on the traverse surface, there is only one contact area between ballast and traverse so the under train wind can move it easy. But when a group of ballasts are accumulated in the track, there are some other contact areas between ballast (interlock force) which can fix the ballast in its position and prevent from motion. The governing force equilibrium can be written as:

$$
\sum \vec{F}=m \vec{a}
$$

where $\vec{a}=a_{x} \hat{i}+a_{y} \hat{j}$ is the resultant acceleration of ballast mass which has two components $a_{x}$ and $a_{y}$ in $\mathrm{X}$ and $\mathrm{Y}$ directions in initiation of ballast flying. As shown in Figure 3, track vibration can help to ballast flying and should be considered in BFPF calculation procedure. Kwon et al. [22] determined BFPF without considering track vibration and in this work for a first time this important parameter is simulated in wind tunnel to access more actual magnitude of BFPF. Also, ballast interlock force acts against the motion of ballast that must be measured experimentally in track model in wind tunnel. This force will be ignored in measurements of BFPF for single ballasts in wind tunnel.

Determination of Ballast flying probability factor (BFPF) is an empirical-analytical method to get the probability of each ballast group under the train wind velocity level. The aim of wind tunnel tests in this work is to measure the critical wind speed for motion of released single ballasts on the traverse surface which is a probable mode in real situation. In this method a row of ballasts from 
a specific mass range should be placed on the traverse surface in test section and then air velocity is increased to move ballasts. The air velocity that leads to motion of first and last ballast at each group should be recorded. The ballast flying probability factor (BFPF) in each mass range due to the passage of high speed train can be estimated by equation (5) [22]:

$$
\left\{\begin{array}{l}
\text { If } V_{\text {Wind }}<V_{\min } \Rightarrow \mathrm{BFPF}=0 \\
\text { If } V_{\text {Wind }}>V_{\text {max }} \Rightarrow \mathrm{BFPF}=1 \\
\text { If } V_{\text {min }}<V_{\text {Wind }}<V_{\max } \Rightarrow \\
\mathrm{BFPF}=\int_{m_{1}}^{m_{2}} \frac{V_{\text {Wind }}-V_{\min }}{V_{\text {max }}-V_{\min }} \frac{d_{m}}{m_{2}-m_{1}}
\end{array}\right.
$$

where $V_{\text {Wind }}$ is the intensity of wind velocity profile under train that is estimated at Section 2.1, $V_{\min }$ is the critical air velocity that leads to motion of first ballast in the specific mass range and $V_{\max }$ is the air velocity that leads to motion of the last sample ballast on that group, $m_{1}$ is the lower and $m_{2}$ is the upper limit of mass of that group and $m$ is the sample ballast mass. The consideration of track vibration in wind tunnel to calculate the BFPF is one of the innovations in this work. For comparison of result, the wind tunnel test is repeated again for the specified ballast group, without track vibration. The results can be used to test a new strategy for risk mitigation of ballast in accumulated mode in track surface considering the inter-locking forces.

\section{Experimental test setup}

The tests of this work are done with the wind tunnel at school of railway engineering in Iran University of Science and Technology (IUST). The tunnel has a square cross section of $0.4 \mathrm{~m} \times 0.4 \mathrm{~m}$ with maximum uniform air flow of $30 \mathrm{~m} / \mathrm{s}$. Air velocity is measured by a dynamic pressure anemometer with $0.01 \mathrm{~m} / \mathrm{s}$ resolution and $2.5 \%$ accuracy. Due to simulation of ballasted track in tunnel a simple model with $0.4 \mathrm{~m}$ width is created which composed of two traverse and ballasts between them as shown in Figure 4. Construction of this model leads to increase of air velocity up to $38 \mathrm{~m} / \mathrm{s}$ over track surface, due to reduction of tunnel cross section.

According to field measurements [15] the intensity of air flow inside the track is greater than outside. Therefore the probability of ballast flying would be critical in this region. Other experiment [5] is shown that the maximum velocity occurs at middle zones of inside track region. In the other word the middle zone of track inside is the most important region or critical region for initiation of flying ballast. Regarding these points the middle zone of an actual track is modeled in wind tunnel with $0.4 \mathrm{~m}$ width. At first step a model of wooden traverse is cut and two parts with $0.4 \mathrm{~m}$ length are made. The two traverse models are installed in the tunnel with specific distance of $0.6 \mathrm{~m}$ according to actual track conditions, and the ballasts are set between them and model of track is completed as shown in Figure 4b,c. Moving velocity of released ballasts at two probable test scenarios are measured, first by putting

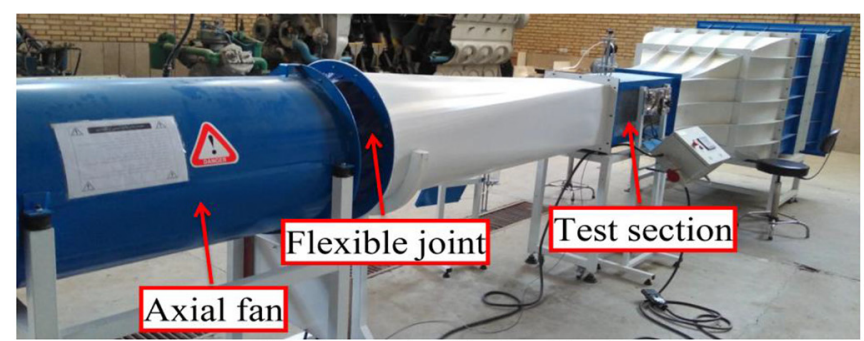

a. Wind tunnel with flexible joint

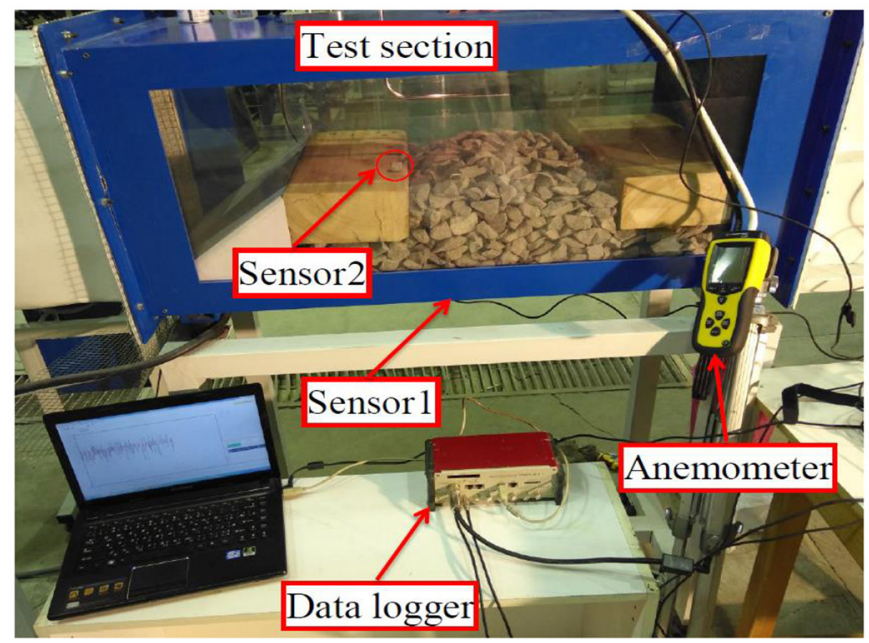

b. Test setup

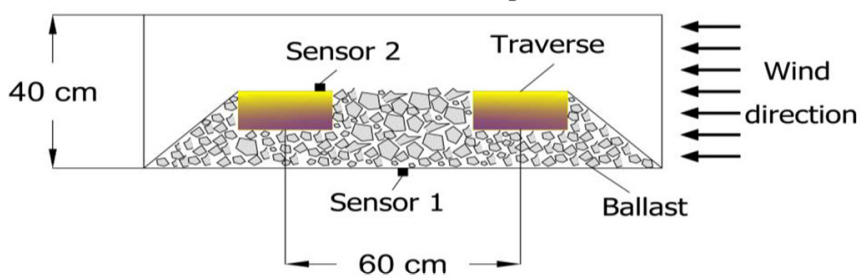

c. Schematic of location of sensors in test section

Fig. 4. Simulation of track model in wind tunnel.

ballasts at top of the traverse to test the critical velocity of single ballast and next by testing the accumulated ballasts on the track surface between two traverses. To simulate actual track conditions in wind tunnel, a vibration with specific acceleration domain is entered to track model. The track vibration is produced by removing the flexible joint between the axial fan and test section. The vibration is simply produced by the unbalance mass on axial fan which is transferred to the test section by the diffuser structure as shown in Figure 4a. The magnitude of vertical acceleration is measured by two accelerometers and data logger that one of them is set under the test section (Sensor1) and the other on top of the traverse (Sensor2). The locations of accelerometers are shown in Figure 4b, c and measured data are shown in Figure 5.

The acceleration data shows the specified value $3-4 \mathrm{~m} / \mathrm{s}^{2}$ on the traverse surface which is in acceptable range according to the EN14363 standard [36].

\subsection{Released single ballast}

According to the literature calculation of BFPF for each ballast group must be done for single ballast over the 


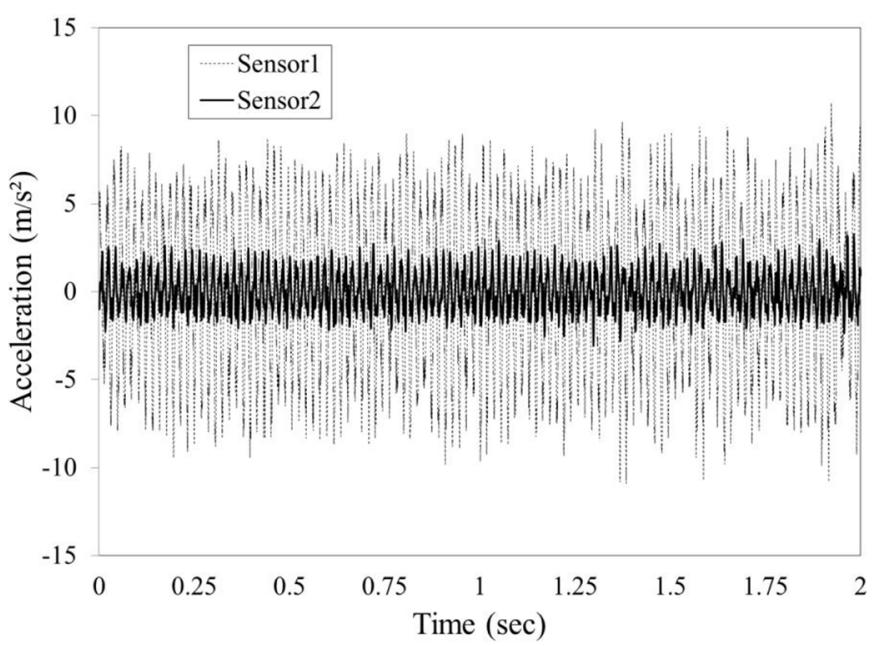

Fig. 5. Measured acceleration by two sensors in wind tunnel.

surface [22]. Due to determination of critical wind velocity for mitigation of each ballast group, the test setup is arranged with ballasts on the traverse. Thus in each test a number of ballast adopted from a specific shape group and mass range is set over the traverse surface under controlled wind velocity. One of our novelties in this work is to calculate the BFPF factor considering the track vibration. Thus we provide a track model with acceptable vibration over its surface for calculation of BFPF on it. In addition it can be said that imposing single ballast over a traverse is usually probable according to the studies in flying ballast phenomenon. At each test the air velocity which leads to first ballast moving is saved as $V_{\min }$ and the last ballast moving velocity as $V_{\max }$ for calculation of BFPF. Figure 6 shows the specified above two moments for ballasts with spherical shape and mass range of $0-50 \mathrm{~g}$ in tunnel test section. This test method is done three times for all shape groups and mass ranges and measured data are used to calculation of BFPF at two modes of with track vibration and without vibration.

\subsection{Ballast flying risk mitigation methods}

With regards to the importance of flying ballast phenomenon and its side effects such as wheel and rail damages and injured workers around high speed track, some countermeasure and control approaches are used to minimize the risk of ballast flight in all countries that have high speed ballasted track. The ballast bags are used at high speed Japanese railway track. In some European countries such as Italy, France and Spain lowering the ballast surface $(2-3 \mathrm{~cm})$ from traverse top surface is the master method for prevention of flying ballast [21]. Here in this paper, these risk mitigation methods are reviewed and confirmed by testing in wind tunnel considering track vibration.

Due to determination of flying ballast wind velocity in usual arrangement of ballast on track, the track model in real mode considering interlock force between ballasts and track vibration is done in wind tunnel. Finally in this paper, a new ballast mitigation strategy is introduced and tested considering the results of BFPF calculation. Then the

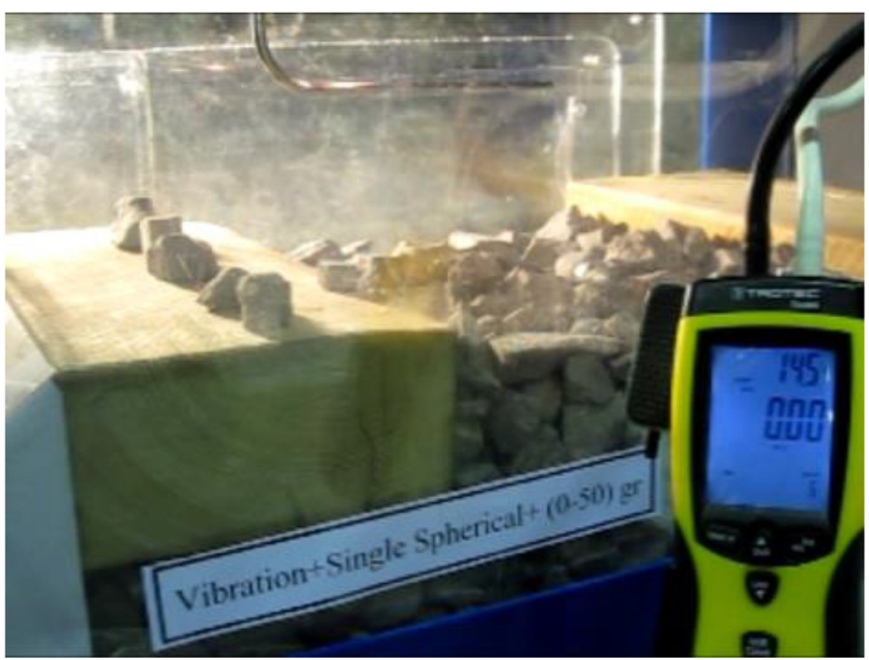

a. Pre test
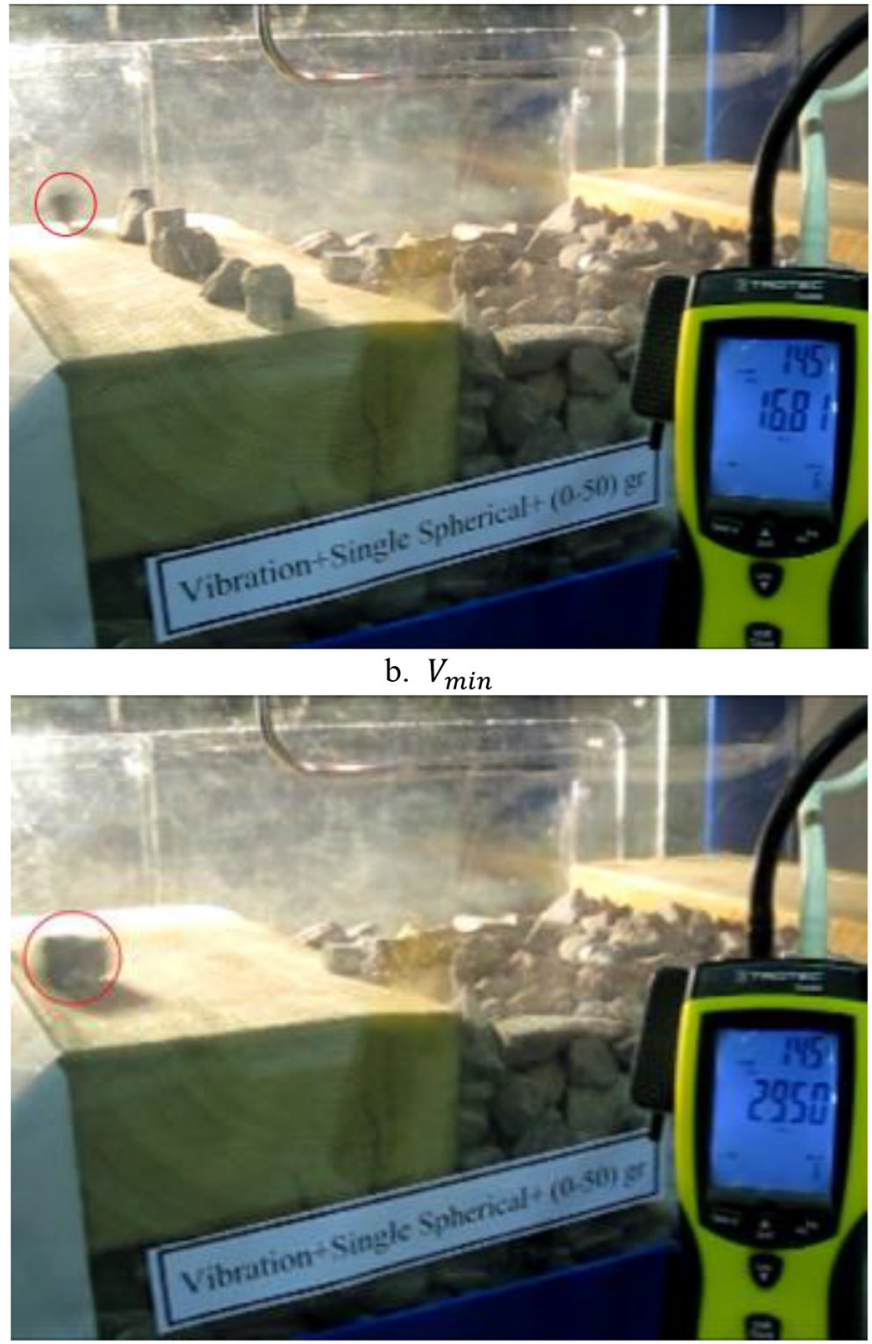

c. $V_{\max }$

Fig. 6. The sample concept of $V_{\min }$ and $V_{\max }$ for spherical ballast in mass range of $0-50 \mathrm{~g}$.

efficiency level and reliability of this new strategy is approved by testing in the wind tunnel model considering track vibration. 


\section{Results and discussion}

Experimental wind tunnel tests are done to earn a new steady and practical strategy for ballast flight risk mitigation in high speed railway. According to this goal the BFPF is estimated considering actual track conditions with vibration and then the ballast mass range that has minimum BFPF is suggested for new strategy of control of flying ballast for high speed line of $300 \mathrm{~km} / \mathrm{h}$.

\subsection{Ballast flying probability factor (BFPF)}

Due to the specific aerodynamic properties of all typical ballasts, the velocity magnitudes for $V_{\min }$ and $V_{\max }$ at each mass group is obtained and a specific trend line is fitted on the measured data. The trend lines are best fitted by a quadratic polynomial equation and used for BFPF calculation. The magnitude of measured $V_{\min }$ and $V_{\max }$ and their trend lines for all mass ranges of ballasts with flat, semi-spherical and spherical aerodynamic shapes are shown in Figure $7 \mathrm{a}-\mathrm{c}$. The BFPF is calculated according to the equation (5), in both modes of considering simulated track vibration and without vibration in wind tunnel.

Figure 7a shows that applying track vibration leads to decrease both velocity magnitudes of $V_{\min }$ and $V_{\max }$. It can be seen that the maximum critical velocities occurs in mass range of $150-200 \mathrm{~g}$ and the critical velocity of ballast moving is decreased for higher mass range (for example 200-250 g) due to the increase of ballast surface against the wind. Due to this phenomenon it can be anticipated that minimum BFPF would be occurred for the ballasts at mass range of $150-200 \mathrm{~g}$. Equation (6) shows the quadratic polynomial equations of trend lines in Figure 7a.

$$
\left\{\begin{array}{l}
\left(V_{\min }\right)_{\text {Flat }, \text { Without vibration }}=-0.0003 \mathrm{~m}^{2}+0.128 \mathrm{~m}+16.989 \\
\left(V_{\max }\right)_{\text {Flat,Without vibration }}=-0.0005 \mathrm{~m}^{2}+0.129 \mathrm{~m}+29.389 \\
\left(V_{\min }\right)_{\text {Flat }, \text { With vibration }}=-0.0002 \mathrm{~m}^{2}+0.0923 \mathrm{~m}+17.432 \\
\left(V_{\max }\right)_{\text {Flat,With vibration }}=-0.0002 \mathrm{~m}^{2}+0.054 \mathrm{~m}+29.753
\end{array}\right.
$$

The behavior of semi-spherical ballasts is approximately similar to the flat ballasts and confirms that ballast moving occurs at lower wind speeds with regards to track vibration. The quadratic polynomial equations of trend lines in Figure $7 \mathrm{~b}$ are defined as equation (7).

\section{See equation (7) below.}

As the both previous ballast groups, the behavior of spherical ballasts changes in mass range of $150-200 \mathrm{~g}$ and this means that all three shapes of ballast in this mass range have a similar reaction when are exposed to the strong wind of under high speed train. Therefore new ballast flying risk mitigation method can be defined based on the minimum BFPF of this mass range. Quadratic polynomial equations of trend lines in Figure 7c are defined as equation (8).

$$
\left\{\begin{array}{l}
\left(V_{\min }\right)_{\text {Spherical, Withoutvibration }}=-0.0002 \mathrm{~m}^{2}+0.0757 \mathrm{~m}+18.23 \\
\left(V_{\max }\right)_{\text {Spherical, Withoutvibration }}=-0.0001 \mathrm{~m}^{2}+0.0492 \mathrm{~m}+28.489 \\
\left(V_{\min }\right)_{\text {Spherical,Withvibration }}=-0.0002 \mathrm{~m}^{2}+0.0965 \mathrm{~m}+15.321 \\
\left(V_{\max }\right)_{\text {Spherical,Withvibration }}=-0.0001 \mathrm{~m}^{2}+0.0596 \mathrm{~m}+26.911
\end{array}\right.
$$

Finally relations of equations (6)-(8) are used for calculation of BFPF for all mass ranges of each shape group according to equation (5) for the train velocity of $300 \mathrm{~km} / \mathrm{h}$ and under train wind velocity of $30.7 \mathrm{~m} / \mathrm{s}$, as introduced in Table 2.

Table 2 shows that track vibration consideration leads to BFPF increase that can be expected due to the effect of track vibration on vertical motion of ballast. The other important result is the effect of ballast shape on BFPF that is demonstrated in Table 2 which flat and spherical groups have minimum and maximum $\mathrm{BFPF}$, respectively. At single ballast test process, flat ballasts usually have small surface exposed to wind unlike spherical and this can lead to ballast moving at higher air velocities. Regarding to interlock force between ballasts in actual track conditions, it is expected that ballast flight risk would be minimized if the mass range of $150-200 \mathrm{~g}$ with minimum BFPF is employed over track surface.

\subsection{New strategy for risk mitigation}

Some methods are used to control ballast flight at all over the world such as using ballast bag and lowering the ballast surface from track. General conditions of these approaches are simulated at our track model with vibration in wind tunnel to show the stability of ballasts up to the wind velocity of $36 \mathrm{~m} / \mathrm{s}$. Results show the efficiency and effectiveness of both tested approaches for a high speed track with passing trains at maximum speeds of $300 \mathrm{~km} / \mathrm{h}$ that generates the maximum under train wind of $30.7 \mathrm{~m} / \mathrm{s}$. But mentioned approaches have some difficulties in application and maintenance such as need to replacement of the bags for track maintenance in Japanese approach and increase of tamping frequency and protect of track lateral resistance in European approach [21]. Figure 8a, b shows the aerodynamic test process of mentioned approaches in wind tunnel.

$$
\left\{\begin{array}{l}
\left(V_{\min }\right)_{\text {Semi-spherical, Without vibration }}=-0.0004 \mathrm{~m}^{2}+0.1356 \mathrm{~m}+16.783 \\
\left(V_{\max }\right)_{\text {Semi-spherical, Without vibration }}=-0.0001 \mathrm{~m}^{2}+0.0357 \mathrm{~m}+30.352 \\
\left(V_{\min }\right)_{\text {Semi-spherical, With vibration }}=-0.0003 \mathrm{~m}^{2}+0.042 \mathrm{~m}+18.817 \\
\left(V_{\max }\right)_{\text {Semi-spherical, With vibration }}=-0.0001 \mathrm{~m}^{2}+0.0409 \mathrm{~m}+28.512
\end{array}\right.
$$




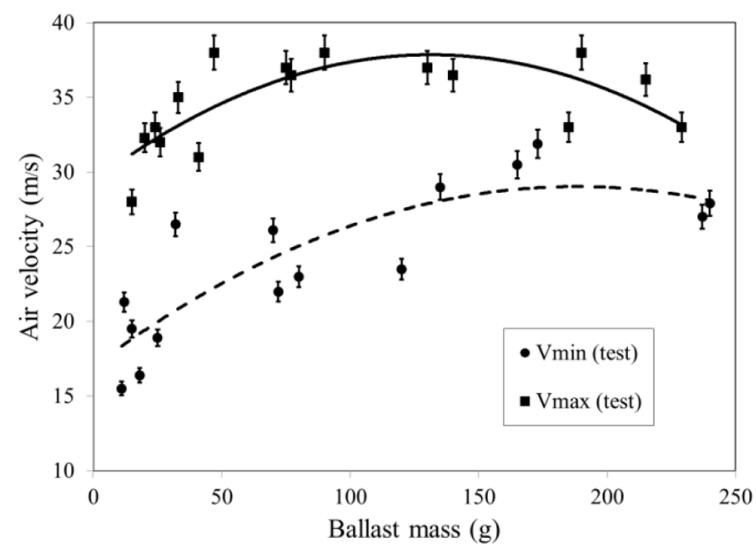

Without track vibration

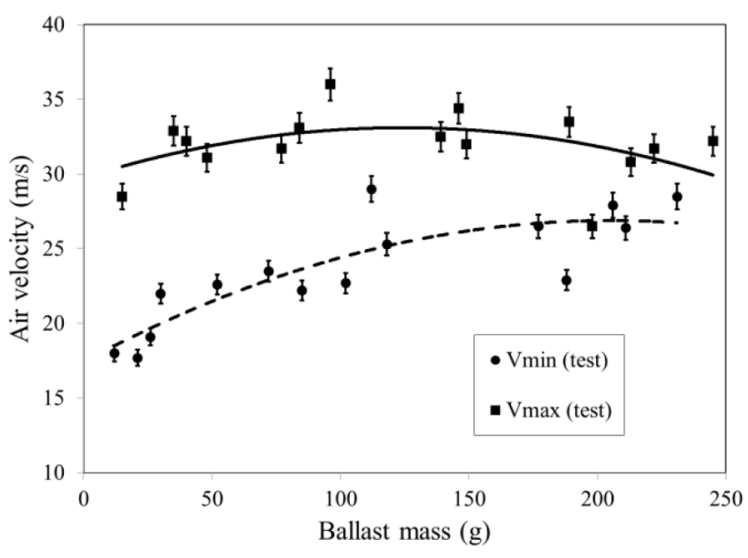

With track vibration

a. Flat ballasts

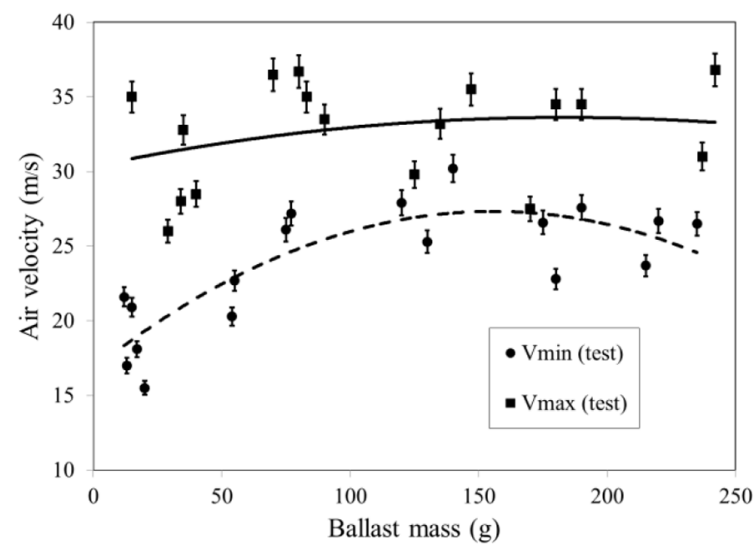

Without track vibration

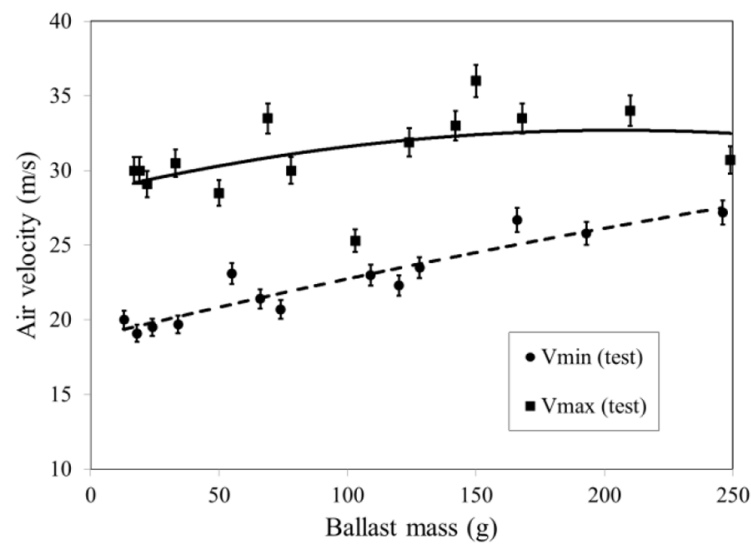

With track vibration

b. Semi-spherical ballasts

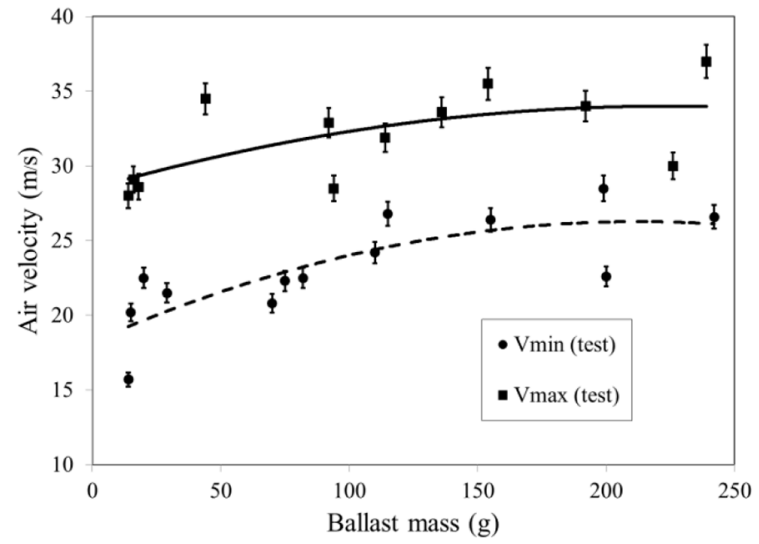

Without track vibration

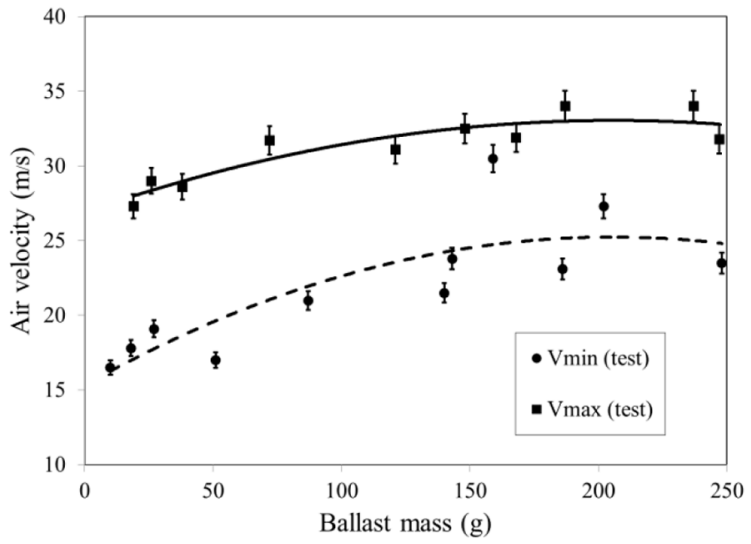

With track vibration

\section{c. Spherical ballasts}

Fig. 7. Measured values of $V_{\min }$ and $V_{\max }$ for ballasts.

A new applicable approach should be defined that needs to minimum construction and be more stable due to passage of high speed train up to $300 \mathrm{~km} / \mathrm{h}$. In this regard, considering minimum $\mathrm{BFPF}$ at specific mass range of $150-200 \mathrm{~g}$ in both test conditions (with and without track vibration) it is intended to cover the track surface with this range. The critical zone of track for initiation of flying ballast is the middle zone around center line of track 
Table 2. Calculated magnitudes of BFPF for a high speed train at speeds of $300 \mathrm{~km} / \mathrm{h}$.

\begin{tabular}{llll}
\hline Ballast Aerodynamic Shape & Mass Range $(\mathrm{g})$ & \multicolumn{2}{l}{ (BFPF) Ballast Flying Probability Factor $(\%)$} \\
\cline { 3 - 4 } & & Without track vibration & With track vibration \\
\hline \multirow{4}{*}{ Flat } & $0-50$ & 87 & 97 \\
& $50-100$ & 51 & 79 \\
& $100-150$ & 25 & 64 \\
& $150-200$ & 8 & 58 \\
& $200-250$ & 20 & 73 \\
\hline \multirow{3}{*}{ Semi-Spherical } & $0-50$ & 95 & 100 \\
& $50-100$ & 77 & 96 \\
& $100-150$ & 56 & 84 \\
& $150-200$ & 47 & 67 \\
& $200-250$ & 58 & 74 \\
\hline \multirow{3}{*}{ Spherical } & $0-50$ & 100 & 100 \\
& $50-100$ & 89 & 98 \\
& $100-150$ & 72 & 75 \\
& $150-200$ & 61 & 56 \\
& $200-250$ & 59 & 45 \\
\hline
\end{tabular}

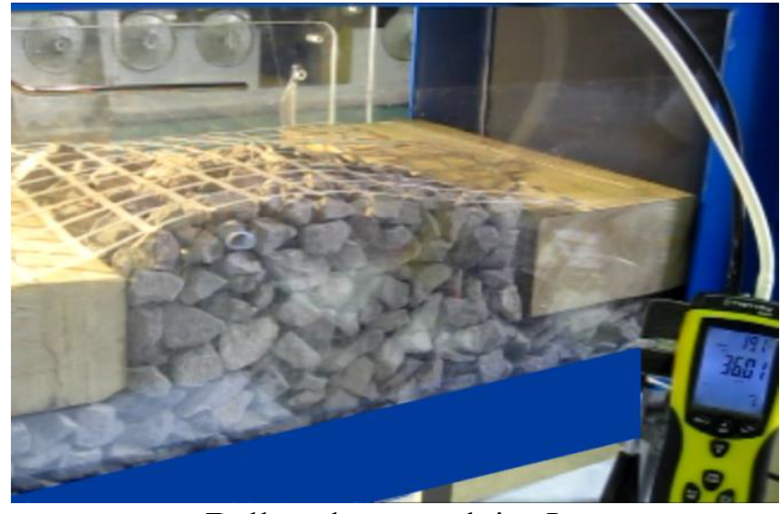

a. Ballast bag used in Japan

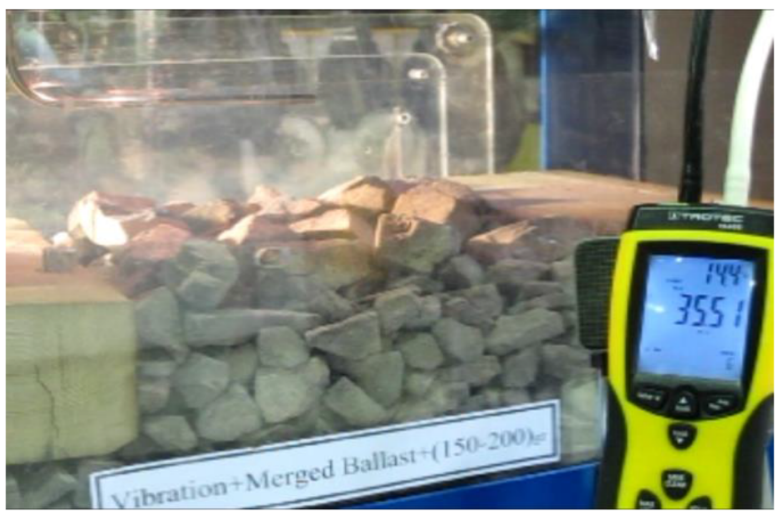

c. New strategy

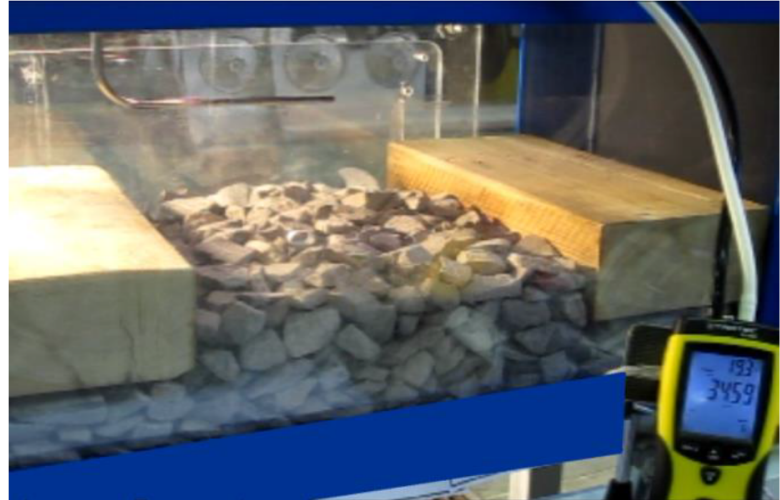

b. Ballast lowering used in Europe

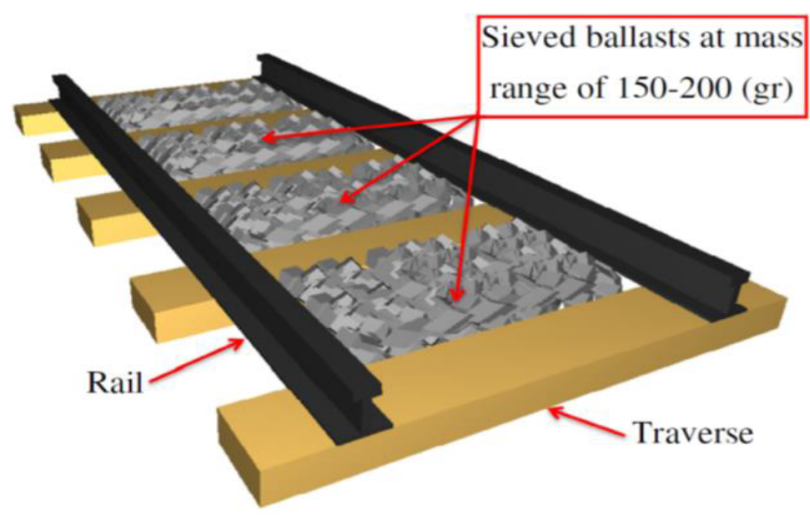

d. Schematic of new strategy

Fig. 8. Test process of conventional methods and new strategy in wind tunnel.

due to the literature [5]. Thus the ballast cover is designed for inside track surface as shown in Figure 8d.

The advantages of this approach will be simple applicability, low construction and maintenance cost and good stability for high speed trains with maximum speeds of $300 \mathrm{~km} / \mathrm{h}$.

The ballast in railway track has some important roles such as: damping the track vibrations, stabilizing the track 
over the lateral forces and drainage, force transmission from rail to track infrastructure which can be threaten by decrease of the number of ballast in track. In the European approach [21] the ballast height is decreased (about 0.8 to 1.2 in) that can affect the damping process, lateral resistance and quality of force transmission in track height. As discussed in this standard decrease of ballast in track leads to increase of impact from traverse to ballast bed which is called tamping frequency. This phenomenon leads to safety reduction and more major mistakes in high speed transportation. In our new suggested strategy (sieved ballast) all components and original structure of track do not change therefore it can be said that mentioned drawback would not occur in this approach.

This innovative strategy is tested and approved by wind tunnel tests at both track conditions (with and without vibration) and a schematic of its properties is shown in Figure 8c. The air velocity at wind tunnel test section crossed the magnitude of $36 \mathrm{~m} / \mathrm{s}$ as two mentioned conventional method test processes but none of ballasts moved. Test results show that this new strategy can be useful for high speed tracks with maximum allowed speeds of $300 \mathrm{~km} / \mathrm{h}$ just with selection of ballast in range of 150-200 g by simple screening on the track surface.

\section{Conclusions}

Ballast flying probability factor (BFPF) is estimated and compared by wind tunnel tests at two test modes of with and without track vibration. At First the critical wind speeds for moving of ballasts due to under train produced wind without track vibration is measured that is the conventional BFPF calculation method [22]. Here in this work for a first time the test process also is done applying the track vibration in wind tunnel. As expected the results show BFPF increases due to the track vibration and it can be said that second test scenario can simulate more real conditions of actual track for study of flying ballast. Furthermore with regards to BFPF arrangement, a new risk mitigation strategy for high speed tracks with maximum train speeds of $300 \mathrm{~km} / \mathrm{h}$ is defined and tested in wind tunnel. Test results show that ballasts at mass range of 150-200 g usually have the minimum magnitude of BFPF at all aerodynamic shapes and ballast flight won't occur with covering the track surface by this range. This new strategy is so applicable with more stable conditions and lower construction and maintenance cost compared with other conventional methods.

\section{References}

[1] C. Baker, The flow around high speed trains, J. Wind Eng. Ind. Aerodyn. 98, 277-298 (2010)

[2] C. Baker, A review of train aerodynamics Part 1-Fundamentals, Aeronaut. J. 118, 201-228 (2014)

[3] M. Bocciolone, F. Cheli, R. Corradi, S. Muggiasca, G. Tomasini, Crosswind action on rail vehicles: wind tunnel experimental analyses, J. Wind Eng. Ind Aerodyn. 96, 584$610(2008)$
[4] F. Cheli, F. Ripamonti, D. Rocchi, G. Tomasini, Aerodynamic behaviour investigation of the new EMUV250 train to cross wind, J. Wind Eng. Ind. Aerodyn. 98, 189-201 (2010)

[5] P. Deeg, M. Jönsson, H.-J. Kaltenbach, M. Schober, M. Weise, Cross-comparison of measurement techniques for the determination of train induced aerodynamic loads on the track bed, Proceedings of the BBAA VI, Milano, Italy (2008) $20-24$

[6] P. Derkowski, S. Clark, R. Sturt, A. Keylin, C. Baker, A. Vardy, N. Wilson, High-Speed Rail Aerodynamic Assessment and Mitigation Report. U.S. Department of Transportation Federal Railroad Administration, 2015

[7] B. Diedrichs, M. Sima, A. Orellano, H. Tengstrand, Crosswind stability of a high-speed train on a high embankment, Proc. Inst. Mech. Eng. F 221, 205-225 (2007)

[8] T. Gilbert, C. Baker, A. Quinn, Gusts caused by high-speed trains in confined spaces and tunnels, J. Wind Eng. Ind. Aerodyn. 121, 39-48 (2013)

[9] H. Hemida, C. Baker, G. Gao, The calculation of train slipstreams using large-eddy simulation, Proc. Inst. Mech. Eng. F 228, 25-36 (2014)

[10] S. Huang, H. Hemida, M. Yang, Numerical calculation of the slipstream generated by a CRH2 high-speed train, Proc. Inst. Mech Eng. F 230, 103-116 (2016)

[11] V. Sarafrazi, M.R. Talaee, CFD Simulation of High-speed Trains: Train-induced Wind Conditions on Trackside Installations, Int. J. Railway Res. 5, 49-62 (2018)

[12] A. Martínez, E. Vega, J. Gaite, J. Meseguer, Pressure measurements on real high-speed trains travelling through tunnels, in Proceedings of BBAA VI International Colloquium on Bluff Bodies Aerodynamics \& Applications, Milano, Italy (2008)

[13] J. Novák, Single train passing through a tunnel, ECCOMAS CFD 2006: Proceedings of the European Conference on Computational Fluid Dynamics, Egmond aan Zee, The Netherlands. Delft University of Technology; European Community on Computational Methods in Applied Sciences (ECCOMAS), September 5-8 (2006)

[14] A. Orellano, Aerodynamics of High Speed Trains (2010)

[15] A. Quinn, M. Hayward, Full-scale aerodynamic measurements underneath a high speed train, in Proceedings of the BBAA VI, Milano, Italy (2008) 1-9

[16] R.S. Raghunathan, H.-D. Kim, T. Setoguchi, Aerodynamics of high-speed railway train, Progr. Aerospace Sci. 38, 469 $514(2002)$

[17] S.-S. Ding, Q. Li, A.-Q. Tian, J. Du, J.-L. Liu, Aerodynamic design on high-speed trains, Acta Mech. Sin. 32, 215-232 (2016)

[18] D. Guo, K. Shang, Y. Zhang, G. Yang, Z. Sun, Influences of affiliated components and train length on the train wind, Acta Mech. Sin. 32, 191-205 (2016)

[19] S. Li, Z. Zheng, J. Yu, C. Qian, Dynamic simulation and safety evaluation of high-speed trains meeting in open air, Acta Mech. Sin. 32, 206-214 (2016)

[20] V. Sarafrazi, M.R. Talaee, Numerical simulation of sand transfer in wind storm using the Eulerian-Lagrangian twophase flow model, Eur. Phys. J. E 42, 45 (2019)

[21] M. Saat, F. Bedini-Jacobini, E. Tutumluer, C. Barkan, Identification of High-Speed Rail Ballast Flight Risk Factors and Risk Mitigation Strategies. U.S. Department of Transportation Federal Railroad Administration, 2015

[22] H. Kwon, C. Park, An experimental study on the relationship between ballast flying phenomenon and strong wind 
under high speed train, in Proceedings of the World Congress on Rail Research, Montreal, QC, Canada (2006)

[23] A. Ido, S. Saitou, K. Nakade, S. Iikura, Study on under-floor flow to reduce ballast flying phenomena, in Proceedings of the World Congress on Rail Research, Seoul, South Korea. 2008

[24] A. Quinn, M. Hayward, C. Baker, F. Schmid, J. Priest, W. Powrie, A full-scale experimental and modelling study of ballast flight under high-speed trains, Proc. Inst. Mech. Eng. F 224, 61-74 (2010)

[25] B.J. Lazaro, E. Gonzalez, M. Rodriguez, Characterization and modeling of flying ballast phenomena in high-speed train lines, The ninth world congress on railway research (2010)

[26] D. Rocchi, P. Schito, G. Tomasini, S. Giappino, A. Premoli, Numerical-experimental study on flying ballast caused by high-speed trains, in Proceedings of the European and African Conference on Wind Engineering, Cambridge, England. 2013

[27] A. Premoli, D. Rocchi, P. Schito, C. Somaschini, G. Tomasini, Ballast flight under high-speed trains: Wind tunnel full-scale experimental tests, J. Wind Eng. Ind. Aerodyn. 145, 351-361 (2015)

[28] R.S. Barbosa, New method for railway track quality identification through the safety dynamic performance of instrumented railway vehicle, J. Br. Soc. Mech. Sci. Eng. 38, 2265-2275 (2016)
[29] J.-D. Yau, L. Frýba, A quasi-vehicle/bridge interaction model for high speed railways, J. Mech. 31, 217-225 (2015)

[30] M. Naeimi, J.A. Zakeri, M. Esmaeili, M. Mehrali, Dynamic response of sleepers in a track with uneven rail irregularities using a 3D vehicle-track model with sleeper beams, Arch. Appl. Mech. 85, 1679-1699 (2015)

[31] R. Bogacz, W. Czyczuła, R. Konowrocki, Effect of periodicity of railway track and wheel-rail interaction on wheelset-track dynamics, Arch. Appl. Mech. 85, 1321-1330 (2015)

[32] A. Metrikine, A. Bodare, Identification of effective properties of the railway substructure in the low-frequency range using a heavy oscillating unit on the track, Arch. Appl. Mech. 80, 959-968 (2010)

[33] J. García, A. Crespo, A. Berasarte, J. Goikoetxea, Study of the flow between the train underbody and the ballast track, J. Wind Eng. Ind. Aerodyn. 99, 1089-1098 (2011)

[34] IranCode301, Railway track superstructures general technical specifications (2005)

[35] G. Jing, Y. Zhou, J. Lin, J. Zhang, Ballast flying mechanism and sensitivity factors analysis, Int. J. Smart Sens. Intell. Syst. 5, 928-939 (2012)

[36] B. EN14363, Railway applications-testing for the acceptance of running characteristics of railway vehicles-testing of running behaviour and stationary tests (2016)

Cite this article as: M.R. Talaee, B. Hakimzadeh, Experimental study of flying ballast at high speed railway applying track vibration, Mechanics \& Industry 21, 401 (2020) 